\title{
Schema therapy for chronic depression: Results of a multiple single case series
}

Citation for published version (APA):

Renner, F., Arntz, A., Peeters, F., Lobbestael, J., \& Huibers, M. J. H. (2016). Schema therapy for chronic depression: Results of a multiple single case series. Journal of Behavior Therapy and Experimental Psychiatry, 51, 66-73. https://doi.org/10.1016/j.jbtep.2015.12.001

Document status and date:

Published: 01/06/2016

DOI:

10.1016/j.jbtep.2015.12.001

Document Version:

Publisher's PDF, also known as Version of record

Document license:

Taverne

Please check the document version of this publication:

- A submitted manuscript is the version of the article upon submission and before peer-review. There can be important differences between the submitted version and the official published version of record.

People interested in the research are advised to contact the author for the final version of the publication, or visit the DOI to the publisher's website.

- The final author version and the galley proof are versions of the publication after peer review.

- The final published version features the final layout of the paper including the volume, issue and page numbers.

Link to publication

\footnotetext{
General rights rights.

- You may freely distribute the URL identifying the publication in the public portal. please follow below link for the End User Agreement:

www.umlib.nl/taverne-license

Take down policy

If you believe that this document breaches copyright please contact us at:

repository@maastrichtuniversity.nl

providing details and we will investigate your claim.
}

Copyright and moral rights for the publications made accessible in the public portal are retained by the authors and/or other copyright owners and it is a condition of accessing publications that users recognise and abide by the legal requirements associated with these

- Users may download and print one copy of any publication from the public portal for the purpose of private study or research.

- You may not further distribute the material or use it for any profit-making activity or commercial gain

If the publication is distributed under the terms of Article $25 \mathrm{fa}$ of the Dutch Copyright Act, indicated by the "Taverne" license above, 


\title{
Schema therapy for chronic depression: Results of a multiple single case series
}

\author{
Fritz Renner ${ }^{\mathrm{a}, \mathrm{b}, *},{ }^{1}$, Arnoud Arntz $^{\mathrm{b}, \mathrm{c}}$, Frenk P.M.L. Peeters ${ }^{\mathrm{d}}$, Jill Lobbestael ${ }^{\mathrm{b}}$, \\ Marcus J.H. Huibers ${ }^{e, b}$ \\ a MRC Cognition and Brain Sciences Unit, Cambridge, United Kingdom \\ ${ }^{\mathrm{b}}$ Department of Clinical Psychological Science, Maastricht University, The Netherlands \\ ${ }^{\mathrm{c}}$ Department of Clinical Psychology, University of Amsterdam, The Netherlands \\ ${ }^{\mathrm{d}}$ Department of Psychiatry and Neuropsychology, University Hospital Maastricht, The Netherlands. School for Mental Health and Neuroscience, Faculty of \\ Health, Medicine and Life sciences, Maastricht University, The Netherlands \\ e Department of Clinical Psychology, VU University Amsterdam, The Netherlands
}

\section{A R T I C L E I N F O}

\section{Article history:}

Received 2 July 2015

Received in revised form

26 October 2015

Accepted 1 December 2015

Available online 8 December 2015

\section{Keywords:}

Chronic depression

Schema therapy

Psychological treatment

Single case series

\begin{abstract}
A B S T R A C T
Background and objectives: The aim of this study was to test the effects of individual schema therapy (ST) for patients with chronic depression.

Methods: Using a multiple-baseline single case series design, patients with chronic major depressive disorder $(N=25)$ first entered a $6-24$ weeks baseline phase; this phase functioned as a no-treatment control condition. Then, patients started a 12 week exploration phase during which symptoms and underlying schemas were explored; this phase functioned as an attention control condition. Next, patients received up to 65 sessions of individual ST. The Beck Depression Inventory II (BDI-II) and the Quick Inventory of Depressive Symptomatology (QIDS) were the primary outcome measures. The BDI-II was assessed once a week during all phases of the study resulting in 100 repeated assessments per participant on average. Mixed regression analysis was used to contrast change in symptoms during the intervention with change in symptoms during the baseline and exploration control phases.

Results: When compared to the no-treatment control period, the intervention had a significant, large effect on depressive symptoms (Cohen's $d$ BDI-II $=1.30$; Cohen's $d$ QIDS $=1.22$ ). Effects on secondary continuous outcomes were moderate to large.

Limitations: The small sample size and lack of a control group.

Conclusions: These findings provide evidence that ST might be an effective treatment for patients with chronic depression.
\end{abstract}

(C) 2015 Elsevier Ltd. All rights reserved.

\section{Introduction}

About one in five patients with depression develops a chronic course defined as the presence of depressive symptoms for two years or longer (Keller, Hanks, Kocsis, \& Klein, 1995). Pharmacological and psychotherapeutic interventions for chronic depression are effective but meta analyses have shown that the effect sizes of psychotherapy are generally low $(d=0.23$; Cuijpers et al., 2010) and

\footnotetext{
* Corresponding author. MRC Cognition and Brain Sciences Unit, 15 Chaucer Road, Cambridge CB2 7EF, United Kingdom.

E-mail address: Fritz.Renner@mrc-cbu.cam.ac.uk (F. Renner).

1 Department of Clinical Psychological Science, Maastricht University, P.O. Box 616, 6200 MD Maastricht, The Netherlands.
}

remission rates following treatment with antidepressant medication are usually below 50\% (for a review see: Kocsis, 2003), highlighting the need for treatment innovation for chronic depression. One promising psychotherapeutic intervention in this respect is the cognitive behavioral analysis system of psychotherapy (CBASP) (McCullough, 2003). Randomized controlled trials (RCTs) have shown that CBASP is at least as effective as antidepressant medication (Keller et al., 2000) and regular care (Wiersma et al., 2014) and more effective than regular care at 52 weeks follow-up (Wiersma et al., 2014). Although these findings are promising, about two-thirds of the patients who received CBASP in these studies did not remit, illustrating that there is room for improvement and a need to explore novel treatments for chronic depression. 
Chronic depression is often rooted in traumatic childhood experiences (Wiersma et al., 2009) and personality pathology (Fava et al., 1996; Hayden \& Klein, 2001; Holmstrand, Engström, \& Träskman-Bendz, 2008; Pepper et al., 1995). Current short-term, symptom focused treatments might fall short in addressing these factors sufficiently. We have argued that schema therapy (ST), a psychological treatment with a strong emphasis on childhood experiences and personality pathology, could be an effective treatment for chronic depression (Renner, Arntz, Leeuw, \& Huibers, 2013). ST has established effectiveness in treating borderline (Giesen-Bloo et al., 2006; Nadort et al., 2009; Nordahl \& Nysaeter, 2005) and primarily Cluster-C personality disorders (Bamelis, Evers, Spinhoven, \& Arntz, 2013) and initial evidence suggests that ST could also be an effective treatment for chronic depression: Brewin et al. (2009) reported positive and large effects of imagery rescripting, a key-technique in ST, on depressive symptoms in patients with chronic depression. Carter et al. (2013) found comparable remission rates between a short ST protocol and cognitive therapy (CT) in a RCT (remission rates in ST: $50 \%$; remission rates in CT: 40\%). Malogiannis et al. (2014) tested a longer ST protocol in chronically depressed women in a case series and found large effects on depressive symptoms and approximately $60 \%$ of patients remitted.

Although these initial findings are promising, there is a need to further test the effects of ST for chronic depression with an appropriate amount of sessions. The current study advances previous studies by testing the effects of up to 65 individual sessions of ST in 25 patients with chronic depression using a multiple-baseline single case series design. Single case series are important research designs in the development of new treatments. They are recognized alternatives to cohort and case-control studies and have the advantage of smaller sample sizes compared to RCTs. The strength of the multiple-baseline design used in the current study above a single case series without multiple baselines (Malogiannis et al., 2014 ) is that, comparable to a RCT, symptomatic improvements during treatment can be attributed to the intervention rather than the mere passage of time (Kazdin, 1982). An extra asset of the current study is that, in addition to a random baseline period, we included an exploration phase during which therapists were instructed to not use any interventions aimed at changing symptoms. We hypothesized that ST would lead to a decrease in depressive symptom severity when compared to symptom change during the non-treatment control (baseline) phase or the exploration phase.

\section{Methods}

\subsection{Participants}

Twenty-five patients with chronic depression were recruited from a specialized secondary mental health facility in the Netherlands (RIAGG Maastricht). Table 1 shows demographic and clinical characteristics of the sample. Study procedures were prespecified prior to recruitment (clinicaltrials.gov: NCT01153867). Inclusion criteria were: (a) DSM-IV diagnosis of major depressive disorder for $\geq 2$ years as indicated by the Structured Clinical Interview for DSM-IV Axis-I Disorders (SCID-I; First, Spitzer, Gibbon, \& Williams, 1997); (b) scoring $\geq 20$ on the Beck

\footnotetext{
${ }^{2}$ Since schema therapy is a quite intense intervention we wanted to make sure that participants have a sufficiently high level of depressive symptom severity (i.e. at least moderate levels of depression). This was confirmed by a BDI-II score $>20$ at the screening appointment, indicating at least moderate levels of depression (Beck et al. 1996).
}

Table 1

Overview of the demographic and clinical characteristics of the sample.

\begin{tabular}{|c|c|}
\hline Variable & Mean (SD)/Frequency (\%) \\
\hline Age & $41.36(16.45)$ \\
\hline \multicolumn{2}{|l|}{ Gender } \\
\hline Female & $20(80 \%)$ \\
\hline Male & $5(20 \%)$ \\
\hline \multicolumn{2}{|l|}{ Country of origin } \\
\hline Netherlands & $23(92 \%)$ \\
\hline Other & $2(8 \%)$ \\
\hline \multicolumn{2}{|l|}{ Marital status } \\
\hline Single & $10(40 \%)$ \\
\hline Partner & $6(24 \%)$ \\
\hline Married & $7(28 \%)$ \\
\hline Divorced & $2(8 \%)$ \\
\hline \multicolumn{2}{|l|}{ Education level } \\
\hline Low & $1(4 \%)$ \\
\hline Medium & $8(32 \%)$ \\
\hline High & $16(64 \%)$ \\
\hline \multicolumn{2}{|l|}{ Work situation } \\
\hline Paid work or student & $10(40 \%)$ \\
\hline Unemployed & $3(36 \%)$ \\
\hline Retired & $9(36 \%)$ \\
\hline Other & $3(12 \%)$ \\
\hline BDI-II score at screening & $32.96(9.37)$ \\
\hline \# Previous episodes & $2.80(2.14)$ \\
\hline \multicolumn{2}{|l|}{ Secondary current axis-I diagnosis } \\
\hline None & $14(56 \%)$ \\
\hline Anxiety disorder & $6(24 \%)$ \\
\hline Other & $5(20 \%)$ \\
\hline \multicolumn{2}{|l|}{ Secondary current axis-II diagnosis } \\
\hline None & $9(32 \%)$ \\
\hline Depressive PD & $9(36 \%)$ \\
\hline Avoidant PD & $7(28 \%)$ \\
\hline Obsessive compulsive PD & $6(24 \%)$ \\
\hline Dependent PD & $1(4 \%)$ \\
\hline Antidepressant use at baseline & $11(44 \%)$ \\
\hline
\end{tabular}

Note. BDI-II = Beck Depression Inventory - second edition.

Depression Inventory second edition (BDI-II; Beck, Steer, \& Brown, $1996)^{2}$; (c) age between 18 and 65 years. Exclusion criteria were: a DSM-IV current or past diagnosis of major depression with psychotic features; current or past bipolar disorder; current or past psychotic disorder; alcohol or drug dependence or a autism spectrum disorder, as assessed with the SCID-I. Patients with cluster-A or cluster-B personality disorders, as assessed with the SCID-II, were also excluded. Patients with cluster-A and cluster-B personality disorders were excluded because these personality disorders were viewed as so complex that they would need specialized treatment. Patients with cluster-C personality disorders where not excluded due to the high co-morbidity with chronic depression. Additional exclusion criteria were acute suicide risk and inability to speak and read the Dutch language. Patients taking antidepressant medication were excluded, unless they were stable on medication for at least three months prior to screening. ${ }^{3}$ The study was approved by the medical ethical committee of the University Hospital Maastricht, the Netherlands. Informed consent was obtained after study procedures were explained to participants and all procedures were in line with the Declaration of Helsinki.

\subsection{Design}

A non-concurrent multiple random baseline design (Kazdin, 1982) consisting of three phases was used: 1) A baseline phase consisting of a 6-24 weeks waiting period that served as a no-

\footnotetext{
3 Medication dosage of one participant taking venlafaxine was increased from $75 \mathrm{mg}$ to $150 \mathrm{mg}$ two month prior to start of the study.
} 
treatment control phase. The duration of the baseline phase was quasi-random (dependent on the waiting time at the clinic). 2) An exploration phase lasting 12 weeks with 8-10 exploration-sessions that served as an additional control phase. 3) An intervention phase, consisting of up to 65 individual sessions ST as described below. Therapists were instructed to not exceed a total of 75 sessions (exploration + intervention phase). During all study phases depressive symptom severity and additional outcomes (described in assessments) were repeatedly assessed.

\subsection{Assessments}

Self-report assessments were completed via a web-based system throughout the three study phases and included weekly measures of depressive symptoms (Beck Depression Inventory II; BDI-II) and global functioning (Outcome Rating Scale; ORS) as well as monthly measures of depressive symptoms (Quick Inventory of Depressive Symptomatology; QIDS-SR) and global symptom severity (Brief Symptom Inventory; BSI).

\subsubsection{Primary outcomes}

2.3.1.1. Response, remission and recovery from depression. Treatment response was defined as a 50\% drop in BDI-II scores, from the first baseline assessment to the last intervention assessment. Remission was defined as a mean score of six or lower on the QIDSSR at the last intervention phase assessment, in line with established cutoffs (Rush et al., 2003). Recovery was defined as the absence of a DSM-IV depression diagnosis assessed with the SCID-I at post-treatment.

\subsubsection{Continuous primary outcome measures}

2.3.2.1. Weekly assessment. The BDI-II was used as a weekly measure of depressive symptom severity (Beck et al., 1996). Each of the 21-items of the BDI-II consists of four statements with increasing severity ranging from 0 to 3 , resulting in a total score of $0-63$ with higher scores representing more depressive symptom severity. The instructions of the original BDI-II were modified, asking participants to evaluate depressive symptoms during the past week instead of the past two weeks to match the timeframe of the weekly assessment. The Dutch version of the BDI-II used in this study has good psychometric properties (van der Does, 2002) and had excellent internal reliability in the current study $(\alpha=.91)$.

2.3.2.2. Monthly assessment. The QIDS-SR is a 16 -item self-report instrument measuring depressive symptom severity over the past seven days (Rush et al., 2003). This shortened version of the original 30-item version (Rush, Gullion, Basco, Jarrett, \& Trivedi, 1996) correlates highly with clinical rating scales, such as the Hamilton Rating Scale for Depression (Rush et al., 2003). Internal reliability of the QIDS-SR in the current study was satisfactory $(\alpha=.75)$.

\subsubsection{Continuous secondary outcome measures}

2.3.3.1. Weekly assessment. The ORS is a short, 4-item, self-report instrument measuring individual, interpersonal, and social functioning as well as overall wellbeing (Miller, Duncan, Brown, Sparks, \& Claud, 2003). In the current study the overall wellbeing scale was used in all analyses. The ORS has adequate psychometric properties (Miller et al., 2003).

2.3.3.2. Monthly assessment. The BSI is a 53-items self-report instrument measuring symptomatic distress along nine subscales (Derogatis, 1992). In the current study, the global severity index was used in all analyses. The original 5-point scale was modified to a $100 \mathrm{~mm}$ Visual Analogue Scale (VAS) because VAS scales might be more sensitive to subtle changes (Breivik, Bjornsson, \& Skovlund,
2000). The BSI has good psychometric properties (de Beurs, 2004).

\section{Procedure}

Eligibility assessments, including SCID-I and SCID-II interviews, were conducted by experienced clinicians at the clinic where treatment was provided. Participants who met the inclusion criteria were invited to an initial baseline assessment during which study procedures were explained and informed consent was obtained. Participants then completed the BDI-II and the ORS weekly during the baseline phase, the exploration phase and the intervention phase and the QIDS-SR and the BSI monthly. All questionnaires were completed via a secure web-based system: Participants received an email once a week, on a fixed date, with personal login information. At post-treatment SCID interviews were conducted by the therapists or by an independent research assistant.

\subsection{Schema therapy for chronic depression}

The ST intervention consisted of 8-10 sessions exploration and up to 65 sessions active intervention with a combined maximum of 75 sessions lasting 50 min each. The definite number of sessions was dependent on individual progress in therapy. Therapy was provided in weekly sessions initially and with lower frequency sessions in later stages of treatment by four experienced therapists (experience with ST varying between 5 and 12 years) according to the methods described by Young (Young, Klosko, \& Weishaar, 2003). During the exploration phase the therapist helped the patient to understand the schema concept, to establish relations between their predominant schemas, current problems and developmental history, and to build a therapeutic alliance. In the exploration phase schemas and current problems are explored but no active attempts are made to change schemas or resolve current problems. Although the exploration phase in the current study was designed as an attentional control phase, it should be noted that the work that is conducted during this phase is of high clinical importance. For example, understanding the links between past experiences and current problems as well as the formation of a strong therapeutic relationship builds the basis for subsequent therapeutic work conducted during the intervention phase. Moreover, the work conducted during the exploration phase might be curative in itself, a possibility that is further described in the discussion. During the intervention phase underlying schemas are targeted by the use of cognitive techniques, experiential techniques, the therapeutic alliance (limited reparenting), and behavioral techniques (as described in: Young et al., 2003). Towards the end of the intervention phase a relapse prevention plan is established and coping strategies to deal with situations that might trigger relapses are established. A detailed description of the treatment manual of ST for chronic depression that was followed in this study is available elsewhere (Renner et al., 2013).

\section{Data analysis}

Statistical analyses of baseline and treatment effects were based on the methods described in (Arntz, Sofi, \& van Breukelen, 2013; Malogiannis et al., 2014). Change in continuous primary and secondary outcome measures during the different treatment phases was modelled using mixed regression analyses in SPSS version 22. All available data was used for intent-to-treat principles.

First, we checked if symptoms remained stable in the absence of treatment (baseline phase). Optimal model fit for different autoregressive covariance structures (AR1 and ARMA1,1) and different representations of change over time (linear, quadratic, logarithmic) 
was determined by comparing the -2 Log Likelihood value of the different models. The optimal model for the main continuous outcome measure (BDI-II) had an ARMA1,1 covariance structure for the repeated part with a logarithmic representation of time in the fixed effects part of the model and included random intercepts and slopes in the random part. Change over time was best represented by log-transformed time, thus the fixed effect of log-transformed time was used to test time development of depressive symptoms and secondary continuous outcomes (BSI, ORS) during baseline.

Next, we tested treatment effects of the exploration and intervention phase versus the baseline phase in terms of average scores and linear change within phases. Fixed effects in the model were: a general time effect (coded 0 when the first assessment took place), dummy coded variables for the exploration and treatment phases as a test of differences in average symptom levels within phases relative to baseline, and linear time variables, individually centered within each phase as a test of change in depressive symptoms during the exploration and intervention phase. Again logarithmic transformed time represented the general time effect best. The model included random intercepts but no random slopes due to convergence problems. When the general time effect was nonsignificant the model was re-run without the general time effect.

Strength of treatment effects (Cohen's $d$ ) was calculated based on model estimates by subtracting the last intervention value from the last baseline value and by dividing the result by the SD based on the variance of the random part of the model.

\section{Results}

\subsection{Description of the data}

On average, each participant received 100 weekly assessments during the course of the study (overall completion rate $77 \%$ ).

\subsubsection{Adherence to exploration phase protocol}

Therapists completed a session-report after each session, recording the types of techniques that were used during the session to assess treatment adherence. These exploration phase session reports suggested good adherence to the exploration phase protocol: The most commonly used exploration phase strategies were not aimed to change underlying symptoms or schemas and included techniques for schema-mode identification (23\%), explaining the schema-therapy model and rationale (20\%) and use of techniques to build the therapeutic relationship (19\%). On average, $7 \%$ of the reported techniques used during the exploration phase were intervention techniques, directed towards changing schemas or resolving current problems, such as reparenting or imagery rescripting. Note that the percentage of intervention techniques used during the exploration phase reported here is conservative and potentially an overestimation as the session report checklist only had an option to indicate use of imageryrescripting (intervention technique) but no option to indicate use of diagnostic-imagery (explorative technique). In some instances therapists crossed out the word 'rescripting' but in other instances it was unclear whether diagnostic-imagery or imagery-rescripting was used and in these instances use of imagery during the exploration phase was coded as use of an intervention technique.

\footnotetext{
${ }^{4}$ At the end of the funding period for this study 7 patients out of the 25 patients who originally started with the study were still in treatment, receiving lowfrequency ST (about 1 session per month).
}

\subsection{Number of treatment sessions}

On average, participants received 53 sessions ST (combined exploration and intervention phase; $\mathrm{SD}=14.01 ; \mathrm{min}=24$ $\max =74)$. Patients who completed treatment on average had 55 sessions $(S D=14.56)$ whereas patients who were still in treatment at the end of the study period ${ }^{4}$ had on average 49 sessions $(\mathrm{SD}=13.09)$

\subsection{Dropout}

Of the 25 included patients 5 (20\%) dropped out during the baseline period. Three started a symptom focused treatment (two CBT; one antidepressants), one stopped because of a new job and lack of time and one stopped due to unspecified personal reasons.

\subsection{Change in depression severity during baseline}

There was a statistically significant logarithmic decrease in the BDI-II total score during baseline, $\mathrm{B}=-2.03, t(25.83)=-2.56$, $p=.02, d=0.51$, suggesting that depressive symptom severity decreased during the baseline phase. As shown in Fig. 1, symptoms decreased during the first weeks of baseline and then became stable.

\subsection{Primary outcomes}

\subsubsection{Response, remission and recovery}

At the last intervention phase assessment, 8/20 (40\%) patients showed a positive response to treatment, $7 / 20$ (35\%) reached remission and 12/18 (67\%) recovered, i.e. did not meet a DSM-IV diagnosis of depression (two patients could not be reached for the post-treatment SCID).

\subsubsection{Depressive symptom severity}

Treatment effects on continues primary outcome measures (BDI-II and QIDS-SR) are reported in Table 2 and Fig. 2. In the model testing for treatment effects on depressive symptoms, assessed weekly with the BDI-II, (i.e. the slope within the phases relative to the slope of the general time effect), the time-intervention effect was significant, $\mathrm{B}=-0.07, t(68.95)=-2.75, p=.008$, reflecting that the intervention had a significant impact on change in depressive symptoms that exceeded the overall decrease in symptoms over time. The time-exploration phase effect was not significant, $\mathrm{B}=0.14, t(385.99)=0.81, p=.42$, suggesting that depressive symptoms did not change during the exploration phase. The effect size for change in the BDI-II from baseline to posttreatment was $d=1.30$.

Convergent effects were found for depressive symptoms assessed monthly with the QIDS-SR (see Fig. 2 and Table 2). The effect size for the QIDS-SR from baseline to post-treatment was $d=1.22$.

\subsection{Treatment effects on continuous secondary outcome measures}

Treatment effects on continuous secondary outcome measures (BSI and ORS) are reported in Table 3 and Fig. 2. After removing a non-significant general time effect from the model testing change in global symptom severity, there was a significant effect of timewithin intervention phase, $\mathrm{B}=-0.54, t(32.53)=-3.24, p=.003$, indicating that the intervention phase was responsible for the overall decrease in general symptom severity (Table 3; Fig. 2). The effect size for the BSI from baseline to post-treatment was $d=0.86$.

In the model testing change in overall wellbeing, there was a significant effect of time of the intervention phase, $B=0.15$, 


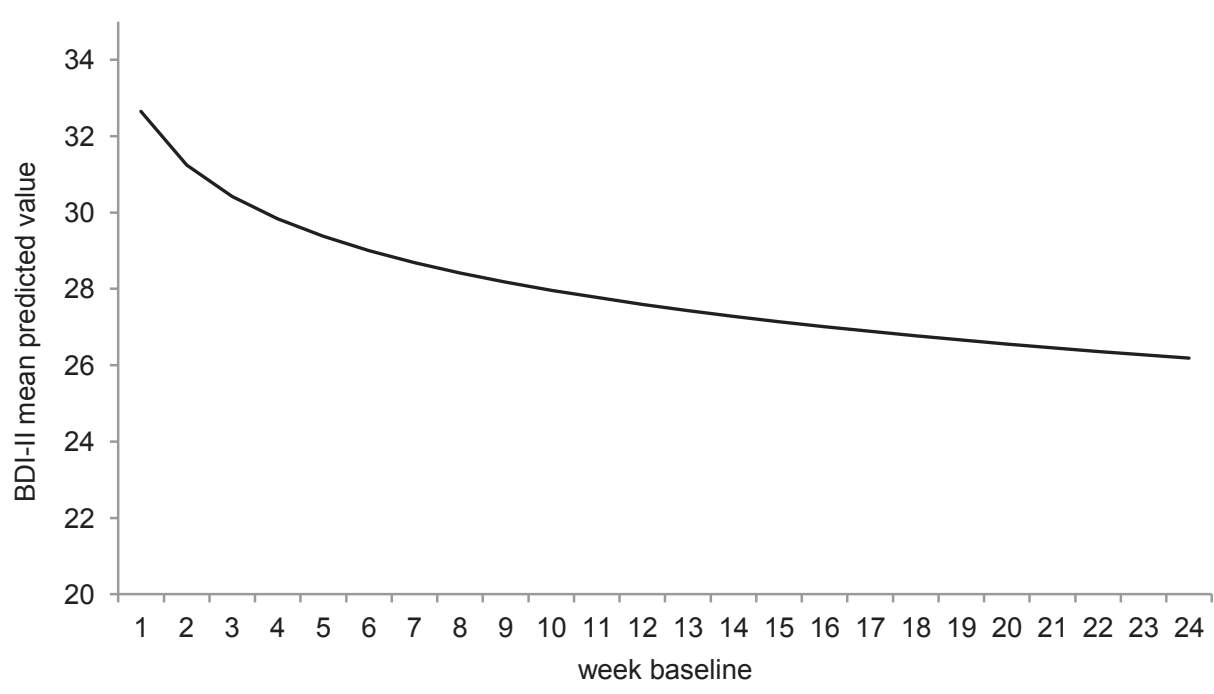

Fig. 1. Graphical representation of decrease in depressive symptoms during baseline.

Table 2

Results of mixed regression analyses testing the effects of schema therapy on primary outcome measures.

\begin{tabular}{llllll}
\hline \multicolumn{1}{c}{ Beta } & $S E$ & $D F$ & $t$ & $p$ \\
\hline BDI-II & & & & & \\
Intercept & 32.92 & 2.32 & 41.47 & 14.19 & $<0.001$ \\
Time $^{1}$ & -2.31 & 0.63 & 567.46 & -3.67 & $<0.001$ \\
Exploration & 2.31 & 1.20 & 505.93 & 1.93 & 0.06 \\
Intervention & -0.88 & 2.03 & 344.49 & -0.44 & 0.66 \\
Time exploration & 0.14 & 0.17 & 385.99 & 0.81 & 0.42 \\
Time intervention & -0.07 & 0.02 & 68.95 & -2.75 & 0.008 \\
QIDS-SR including general time effect & & & & \\
Intercept & 14.94 & 1.11 & 39.31 & 13.51 & $<0.001$ \\
Time & -1.22 & 0.71 & 293.91 & -1.72 & 0.09 \\
Exploration & 0.81 & 0.89 & 234.95 & 0.92 & 0.36 \\
Intervention & -1.29 & 1.61 & 244.13 & -0.80 & 0.43 \\
Time exploration & 0.81 & 0.97 & 290.52 & 0.84 & 0.40 \\
Time intervention & -0.18 & 0.08 & 47.40 & -2.30 & 0.03 \\
QIDS-SR after deleting & ns. general time effect & & & \\
Intercept & 14.27 & 1.03 & 31.69 & 13.79 & $<0.001$ \\
Exploration & -0.35 & 0.58 & 234.32 & -0.60 & 0.55 \\
Intervention & -3.69 & 0.77 & 55.69 & -4.78 & $<0.001$ \\
Time exploration & 0.26 & 0.91 & 308.50 & 0.28 & 0.78 \\
Time intervention & -0.25 & 0.06 & 44.28 & -4.04 & $<0.001$ \\
\hline
\end{tabular}

Note. ${ }^{1} \log$ transformed.

$t(129.37)=4.20, p<.001$ (Table 3; Fig. 2), indicating that the intervention phase led to an increase in overall wellbeing. The effect size for improvements in overall wellbeing from baseline to post-treatment was $d=0.93$.

\section{Discussion}

Many patients with chronic depression do not improve in current pharmacological or psychological treatments for depression highlighting the need of exploring new treatment options for this patient group. The aim of this study was to test the effects of individual schema therapy (ST) in a case-series of 25 patients with chronic depression. We found that $40 \%$ of the patients responded to treatment, $35 \%$ remitted and $67 \%$ recovered, i.e. did not meet the DSM-IV criteria for a depressive disorder at post-treatment. Relative to an overall decrease in symptoms over time, there was a significant effect of the ST intervention on depressive symptoms. After accounting for decreased symptom severity during the baseline phase, by considering the last baseline phase assessments, the effect sizes for improvements in depressive symptoms during the intervention phase were large.

Overall, these findings add to the emerging evidence that ST is a promising treatment for patients with (chronic) depression (Carter et al., 2013; Malogiannis et al., 2014). For example, Malogiannis et al. (2014) conducted a case series for chronically depressed women and found comparable remission (41.6\%) and recovery (60\%) rates. The current study implemented a more stringent control for change in symptoms over time as we implemented multiple quasi-random baselines in our experimental design which might explain the slightly higher remission rates in the study by Malogiannis et al. (2014). In contrast to the current study, Malogiannis et al. (2014) also found effects of the exploration phase (labeled "phase b" or "introduction phase" in their study) on depressive symptom severity. As described by the authors, their exploration phase was not purely exploratory with a strong focus on bonding between patient and therapists that took place in a highly "nurturing environment" which might explain the effects (Malogiannis et al., 2014). In contrast, the exploration phase in the current study was primarily explorative. The absence of symptom change during the exploration phase that was found in the current study is in line with previous studies reporting that exploration of symptoms in the context of developmental history (trauma) does not improve symptoms (Arntz et al., 2013; Weertman \& Arntz, 2007).

The findings of the current study also hint towards potential mechanisms of change in ST for chronic depression. What accounts for change in symptoms in psychotherapy (i.e. treatment mechanisms) has been the topic of an ongoing debate in the literature, with some researchers arguing that treatment-specific factors are responsible for symptom improvements whereas others have argued that so-called common factors, such as the therapeutic alliance, are responsible for (early) change in symptoms (for a recent discussion from both perspectives see e.g.: Hofmann \& Barlow, 2014; Laska, Gurman, \& Wampold, 2014). The exploration phase in the current study primarily included components that are usually considered common factors, such as the formation of a strong therapeutic relationship. The finding that the exploration phase in the current study was not associated with symptom improvement, while the intervention phase did lead to improvement, suggests that common factors in isolation cannot account for (early) symptom change in ST for chronic depression and that it is the addition of specific factors in the intervention phase that 

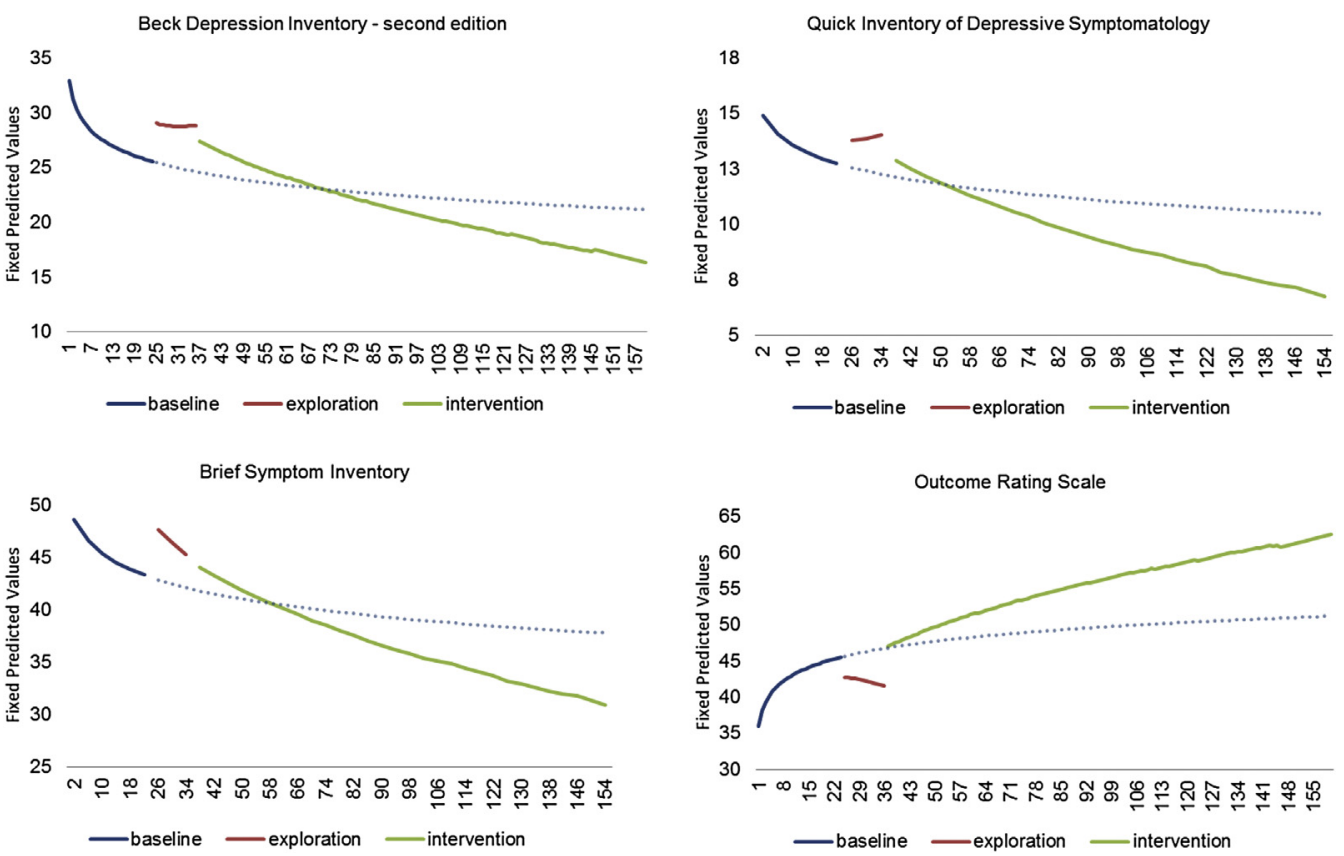

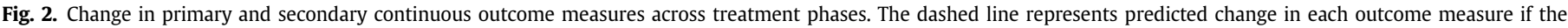
baseline would continue. Higher scores on the Outcome Rating Scale represents better functioning; Lower scores on all other measures represents less symptom severity.

Table 3

Results of mixed regression analyses testing the effects of schema therapy on secondary outcome measures.

\begin{tabular}{llllll}
\hline \multicolumn{1}{l}{ Beta } & $S E$ & $D F$ & $t$ & $P$ \\
\hline BSI & & & & & \\
Intercept & 48.64 & 3.25 & 36.76 & 14.97 & $<0.001$ \\
Time & -2.96 & 1.94 & 313.67 & -1.52 & 0.13 \\
Exploration & 2.32 & 2.41 & 328.83 & 0.96 & 0.34 \\
Intervention & -2.07 & 4.39 & 277.91 & -0.47 & 0.64 \\
Time exploration & -1.00 & 2.56 & 326.30 & -0.39 & 0.70 \\
Time intervention & -0.36 & 0.21 & 86.02 & -1.73 & 0.09 \\
BSI after deleting $n$ ns. general time & effect & & & \\
Intercept & 47.11 & 3.07 & 29.97 & 15.36 & $<0.001$ \\
Exploration & -0.47 & 1.58 & 233.61 & -0.30 & 0.77 \\
Intervention & -7.95 & 2.09 & 30.85 & -3.81 & 0.001 \\
Time exploration & -2.37 & 2.41 & 318.75 & -1.00 & 0.33 \\
Time intervention & -0.54 & 0.17 & 32.53 & -3.24 & 0.003 \\
ORS & & & & & \\
Intercept & 36.00 & 3.91 & 130.40 & 9.20 & $<0.001$ \\
Time & 3.00 & 1.78 & 560.50 & 1.69 & 0.09 \\
Exploration & -2.03 & 3.27 & 509.18 & -0.62 & 0.53 \\
Intervention & 5.44 & 5.05 & 403.39 & 1.08 & 0.28 \\
Time exploration & -0.3 & 0.47 & 568.61 & -0.66 & 0.51 \\
Time intervention & 0.10 & 0.05 & 219.37 & 2.17 & 0.03 \\
ORS after deleting $n s$. general time & effect & & & \\
Intercept & 40.32 & 2.96 & 46.84 & 13.63 & $<0.001$ \\
Exploration & 1.59 & 2.47 & 397.28 & 0.65 & 0.52 \\
Intervention & 13.10 & 2.21 & 177.91 & 5.91 & $<0.001$ \\
Time exploration & 0.01 & 0.43 & 774.10 & 0.03 & 0.98 \\
Time intervention & 0.15 & 0.04 & 129.37 & 4.20 & $<0.001$ \\
\hline Note. ${ }^{1}$ Log transformed & & & & &
\end{tabular}

Note. ${ }^{1}$ Log transformed.

eventually leads to a better outcome. However, this could not be tested directly here and the question of mechanisms of change in ST (for chronic depression) remains an issue for future research.

Although results from case-series cannot directly be compared to meta-analytic findings based on RCTs, the stringent control phases in the current study allowed us to control for a general decrease in symptoms over time (baseline phase) and for possible effects of common factors, including receiving attention and empathy and the formation of a therapeutic relationship (exploration phase). In this regard, the control phases in the current study are comparable to waiting-list control conditions (baseline phase) and non-active control treatment conditions (exploration phase) in RCTs. However, note that the work conducted during the exploration phase is still of high clinical importance as it forms the foundation of the work conducted during the intervention phase. When benchmarking the findings of the current study against the effect size found in a meta-analysis of psychotherapy for chronic depression ( $d=0.23$; Cuijpers et al., 2010), ST in the current study seems to perform well. We also tested for improvements in global symptomatic distress and overall wellbeing as relevant secondary outcomes. Participants improved with moderate to large effect sizes on global symptomatic distress and overall wellbeing, indicating that the positive effects of ST on depressive symptoms extended to broader aspects of distress and functioning.

Although five patients dropped out during the baseline phase none of the participants dropped out from treatment. Studies of ST for personality disorder have reported relatively lower dropout rates in ST compared to treatment as usual (Bamelis et al., 2013) or psychotherapy control conditions (Giesen-Bloo et al., 2006). ST places special emphasis on building a strong therapeutic relationship during the exploration phase (Young et al., 2003) which could protect from dropout. In line with this, it has been shown that negative therapeutic alliance ratings predict dropout, and that the high treatment retention of ST probably relates to early strong therapeutic alliance (Spinhoven, Giesen-Bloo, van Dyck, Kooiman, \& Arntz, 2007). In this sense, the exploration phase in the current study might have had a therapeutic value by protecting from dropout. Note that with the current design this possibility cannot be tested.

The current study included a quasi-random baseline period to control for change in symptoms over time in the absence of active treatment. Unexpectedly, depressive symptoms decreased initially and then became stable during the course of the baseline. At least two explanations might account for this finding. The initial decrease in symptoms during baseline represents 1) a 'true' 
spontaneous improvement in depressive symptoms or 2) a measurement artifact. In favor of the first explanation, participants might have experienced a strong motivation to start with a novel, promising treatment in an academic context. This might have led to an initial alleviation in depressive symptoms during the first weeks of the study (i.e. an expectancy effect). In favor of the second explanation, participants might have overestimated their symptom severity and due to the repeated completion of and reflection on the questionnaires established a new, 'true', stable baseline. In line with this, it has been shown that a change in BDI scores in the absence of treatment is a function of the frequency of test administration with weekly administration resulting in decreases whereas BDI scores remain stable during bi-weekly or monthly administration (Longwell \& Truax, 2005). Moreover, patients with depression become more accurate in assessing self-reported depressive symptoms over time (Fokkema, Smits, Kelderman, \& Cuijpers, 2013). Given that patients in the current study, by definition, suffered from depression for at least two years, it is unlikely that they experienced a 'true' decrease in symptoms during baseline. Note that based on the current study it is not possible to empirically support either explanation. One implication of this finding is that depressed patients participating in treatment outcome studies should be re-assessed until symptom severity is stable instead of relying on one pre-treatment or baseline assessment.

A number of important limitations of this study should be mentioned when interpreting the results. First, this study was a case series which by design does not include a control group. However, by including a non-treatment multiple baseline phase and an exploration phase, symptom improvement over time could be attributed to the intervention. Second, the decrease in depressive symptoms during the baseline phase complicated the detection and estimation of treatment effect sizes. Due to the unstable baseline we had to (implicitly) rely on extrapolation of change assessed during the baseline to the exploration and intervention periods. Third, due to the small sample size we were not able to explore predictors of treatment effects in this study, an important issue for future studies. Finally, post-treatment SCID assessments were conducted by study therapists, who were not blind to the treatment and might therefore have been biased in their judgment which could account for the relatively high recovery rates compared to response and remission rates in this study.

In conclusion, this study adds to the accumulating evidence that ST might be an effective treatment for patients with chronic depression. The low dropout rates in previous ST studies and the absence of dropout from the intervention phase in the current study highlight the acceptability of ST by patients. Although there is now emerging evidence that ST might be an effective treatment for (chronic) depression, future RCT based studies in larger samples are needed to determine the efficacy of ST for chronic depression and the comparative efficacy of ST relative to other interventions before the findings can be disseminated in clinical practice.

\section{Declaration of interest}

None.

\section{Role of the funding source}

Maastricht University and the Academic Community Mental Health Centre Maastricht provided financial support for this study.

\section{Acknowledgements}

The authors would like to thank the participating patients, therapists, research coordinators and research assistants. Maastricht University and the academic community mental health center (RIAGG) Maastricht provided the financial support for this study.

\section{References}

Arntz, A., Sofi, D., \& van Breukelen, G. (2013). Imagery Rescripting as treatment for complicated PTSD in refugees: a multiple baseline case series study. Behaviour Research and Therapy, 51(6), 274-283. http://dx.doi.org/10.1016/ j.brat.2013.02.009.

Bamelis, L. L. M., Evers, S. M. A. A., Spinhoven, P., \& Arntz, A. (2013). Results of a multicentered randomized controlled trial on the clinical effectiveness of schema therapy for personality disorders. American Journal of Psychiatry. http:// dx.doi.org/10.1176/appi.ajp.2013.12040518.

Beck, A. T., Steer, R. A., \& Brown, G. K. (1996). Manual for the beck depression Inventory-II. San Antonio, TX.

de Beurs, E. (2004). De brief symptom Inventroy: Handleiding [The brief symptom Inventroy: Manual]. Leiden: Pits Publishers.

Breivik, E. K., Bjornsson, G. A., \& Skovlund, E. (2000). A comparison of pain rating scales by sampling from clinical trial data. Clinical Journal of Pain, 16(1), 22-28.

Brewin, C. R., Wheatley, J., Patel, T., Fearon, P., Hackmann, A., Wells, A.... Myers, S. (2009). Imagery rescripting as a brief stand-alone treatment for depressed patients with intrusive memories. Behaviour Research and Therapy, 47(7), 569-576. http://dx.doi.org/10.1016/j.brat.2009.03.008.

Carter, J. D., McIntosh, V. V., Jordan, J., Porter, R. J., Frampton, C. M., \& Joyce, P. R. (2013). Psychotherapy for depression: a randomized clinical trial comparing schema therapy and cognitive behavior therapy. Journal of Affective Disorders, 151(2), 500-505. http://dx.doi.org/10.1016/j.jad.2013.06.034.

Cuijpers, P., van Straten, A., Schuurmans, J., van Oppen, P., Hollon, S. D., \& Andersson, G. (2010). Psychotherapy for chronic major depression and dysthymia: a meta-analysis. Clinical Psychology Review, 30(1), 51-62. http:// dx.doi.org/10.1016/j.cpr.2009.09.003.

Derogatis, L. R. (1992). The brief symptom inventory (BSI); administration, scoring and procedures manual-II. Clinical Psychometric Research Inc.

Van der Does, A. J. W. (2002). Handleiding: De Nederlandse versie van de Beck Depression Inventory [/The Dutch version of the Beck Depression Inventory, 2nd ed.]l (2de Editie). Lisse: Swets and Zeitlinger b.v.

Fava, M., Alpert, J., Borus, J., Nierenberg, A., Pava, J., \& Rosenbaum, J. (1996). Patterns of personality disorder comorbidity in early-onset versus late- onset major depression. American Journal of Psychiatry, 153(10), 1308-1312. Retrieved from http://ajp.psychiatryonline.org/cgi/content/abstract/153/10/1308 http://ajp. psychiatryonline.org/article.aspx?articleid =172004.

First, M. B., Spitzer, R. L., Gibbon, M., \& Williams, J. B. (1997). Structured clinical interview for DSM-IV Axis I disorders (SCID-I). New York: Biometrics Research Department.

Fokkema, M., Smits, N., Kelderman, H., \& Cuijpers, P. (2013). Response shifts in mental health interventions: an illustration of longitudinal measurement invariance. Psychological Assessment, 25(2), 520-531. http://dx.doi.org/10.1037/ a0031669.

Giesen-Bloo, J., van Dyck, R., Spinhoven, P., van Tilburg, W., Dirksen, C., van Asselt, T....Arntz, A. (2006). Outpatient psychotherapy for borderline personality disorder: randomized trial of schema-focused therapy vs transferencefocused psychotherapy. Archives of General Psychiatry, 63(6), 649-658. http:/ dx.doi.org/10.1001/archpsyc.63.6.649.

Hayden, E. P., \& Klein, D. N. (2001). Outcome of Dysthymic disorder at 5-Year followup: the effect of familial psychopathology, early adversity, personality, comorbidity, and chronic Stress. American Journal of Psychiatry, 158(11), 1864-1870. http://dx.doi.org/10.1176/appi.ajp.158.11.1864.

Hofmann, S. G., \& Barlow, D. H. (2014). Evidence-based psychological interventions and the common factors approach: the beginnings of a rapprochement? Psychotherapy (Chic), 51(4), 510-513. http://dx.doi.org/10.1037/a0037045.

Holmstrand, C., Engström, G., \& Träskman-Bendz, L. (2008). Disentangling dysthymia from major depressive disorder in suicide attempters' suicidality, comorbidity and symptomatology. Nordic Journal of Psychiatry, 62(1), 25-31. http:// dx.doi.org/10.1080/08039480801960164.

Kazdin, A. E. (1982). Single-case research designs: Methods for clinical and applied settings. New York: Oxford University Press.

Keller, M. B., Hanks, D. L., Kocsis, J. H., \& Klein, D. N. (1995). Course and natural history of chronic depression diagnosis and treatment of chronic depression (pp. 58-72). New York, NY US: Guilford Press.

Keller, M. B., McCullough, J. P., Klein, D. N., Arnow, B., Dunner, D. L., Gelenberg, A. J.... Zajecka, J. (2000). A comparison of nefazodone, the cognitive behavioral-analysis system of psychotherapy, and their combination for the treatment of chronic depression. The New England Journal of Medicine, 342(20), 1462-1470. http://dx.doi.org/10.1056/NEJM200005183422001.

Kocsis, J. H. (2003). Pharmacotherapy for chronic depression. Journal of Clinical Psychology, 59(8), 885-892. http://dx.doi.org/10.1002/jclp.10180.

Laska, K. M., Gurman, A. S., \& Wampold, B. E. (2014). Expanding the lens of evidence-based practice in psychotherapy: a common factors perspective. Psychotherapy, 51(4), 467-481. http://dx.doi.org/10.1037/a0034332.

Longwell, B. T., \& Truax, P. (2005). The differential effects of weekly, monthly, and bimonthly administrations of the beck Depression Inventory-II: psychometric 
properties and clinical implications. Behavior Therapy, 36(3), 265-275. http:// dx.doi.org/10.1016/S0005-7894(05)80075-9.

Malogiannis, I. A., Arntz, A., Spiropoulou, A., Tsartsara, E., Aggeli, A Karveli, S....Zervas, I. (2014). Schema Therapy for patients with chronic depression: a single case series study. Journal of Behavior Therapy and Experimental Psychiatry, 45(3), 319-329. http://dx.doi.org/10.1016/j.jbtep.2014.02. 003.

McCullough, J. P., Jr. (2003). Treatment for chronic depression using cognitive behavioral analysis system of psychotherapy (CBASP). Journal of Clinical Psychology, 59(8), 833-846. http://dx.doi.org/10.1002/jclp.10176.

Miller, S. D., Duncan, B. L., Brown, J., Sparks, J. A., \& Claud, D. A. (2003). The outcome rating scale: a preliminary study of the reliability, validity, and feasibility of a brief visual analog measure. Journal of Brief Therapy, 2(2), 91-100.

Nadort, M., Arntz, A., Smit, J. H., Giesen-Bloo, J., Eikelenboom, M., Spinhoven, P.... van Dyck, R. (2009). Implementation of outpatient schema therapy for borderline personality disorder with versus without crisis support by the therapist outside office hours: a randomized trial. Behaviour Research and Therapy, 47(11), 961-973. http://dx.doi.org/10.1016/j.brat.2009.07.013.

Nordahl, H. M., \& Nysaeter, T. E. (2005). Schema therapy for patients with borderline personality disorder: a single case series. Journal of Behavior Therapy and Experimental Psychiatry, 36(3), 254-264. Retrieved fromhttp://www. sciencedirect.com/science/article/pii/S0005791605000303.

Pepper, C., Klein, D., Anderson, R, Riso, L, Ouimette, P., \& Lizardi, H. (1995). DSM-III$\mathrm{R}$ axis II comorbidity in dysthymia and major depression. American Journal of Psychiatry, 152(2), 239-247. Retrieved from http://ajp.psychiatryonline.org/cgi/ content/abstract/152/2/239.

Renner, F., Arntz, A., Leeuw, I., \& Huibers, M. (2013). Treatment for chronic depression using schema therapy. Clinical Psychology Science and Practice, 20, 166-180. http://dx.doi.org/10.1111/cpsp.12032.

Rush, A. J., Gullion, C. M., Basco, M. R., Jarrett, R. B., \& Trivedi, M. H. (1996). The inventory of depressive symptomatology (IDS): psychometric properties. Psychological Medicine, 26(03), 477-486. http://dx.doi.org/10.1017/ S0033291700035558.

Rush, A. J., Trivedi, M. H., Ibrahim, H. M., Carmody, T. J., Arnow, B., Klein, D. N.... Keller, M. B. (2003). The 16-item Quick Inventory of Depressive Symptomatology (QIDS), clinician rating (QIDS-C), and self-report (QIDS-SR): a psychometric evaluation in patients with chronic major depression. Biological Psychiatry, 54(5), 573-583. http://dx.doi.org/10.1016/S0006-3223(02)01866-8. Retrieved from http://search.ebscohost.com/login.aspx? direct $=$ true $\& \mathrm{db}=$ psyh $\& A N=2003-07477-008 \&$ site $=$ ehost-live $\&$ scope =site.

Spinhoven, P., Giesen-Bloo, J., van Dyck, R., Kooiman, K., \& Arntz, A. (2007). The therapeutic alliance in schema-focused therapy and transference-focused psychotherapy for borderline personality disorder. Journal of Consulting and Clinical Psychology, 75(1), 104-115. http://dx.doi.org/10.1037/0022-006x.75.1.104.

Weertman, A., \& Arntz, A. (2007). Effectiveness of treatment of childhood memories in cognitive therapy for personality disorders: a controlled study contrasting methods focusing on the present and methods focusing on childhood memories. Behaviour Research and Therapy, 45(9), 2133-2143. http://dx.doi.org/10. 1016/j.brat.2007.02.013.

Wiersma, J. E., Hovens, J. G., Van Oppen, P., Giltay, E. J., Van Schaik, D. J., et al. (2009). The importance of childhood trauma and childhood life events for chronicity of depression in adults. Journal of Clinical Psychiatry, 70(7), 983-989.

Wiersma, J. E., Van Schaik, D. J., Hoogendorn, A. W., Dekker, J. J., Van, H. L. Schoevers, R. A....Van Oppen, P. (2014). The effectiveness of the cognitive behavioral analysis system of psychotherapy for chronic depression: a randomized controlled trial. Psychotherapy and Psychosomatics, 83(5), 263-269. http://dx.doi.org/10.1159/000360795.

Young, J. E., Klosko, J., \& Weishaar, M. E. (2003). Schema therapy: A practitioner's guide. New York: Guilford Press. 